\title{
Abruptio placenta retrospective study: maternal and fetal outcome
}

\author{
Shanthadevi Sambath*, Vanitha Rukmani V. H., Subalakshmi S.
}

Department of Obstetrics and Gynecology, Government Theni Medical College and Hospital, Tamil Nadu, India

Received: 26 February 2019

Accepted: 20 March 2019

\section{*Correspondence:}

Dr. Shanthadevi Sambath,

E-mail: devisambath@gmail.com

Copyright: (c) the author(s), publisher and licensee Medip Academy. This is an open-access article distributed under the terms of the Creative Commons Attribution Non-Commercial License, which permits unrestricted non-commercial use, distribution, and reproduction in any medium, provided the original work is properly cited.

\section{ABSTRACT}

Background: Placental abruption is the most common cause of antepartum haemorrhage. Incidence appears to be increasing due to increase in prevalence of risk factors like age, parity, anaemia, poor nutrition, Preeclampsia, PROM, previous MTP. Abruption may be partial or total. Pain and Vaginal bleeding hallmark of abruption.

Methods: Retrospective observational study carried out during period of October 2017 to October 2018 at Govt Theni medical college- tertiary care institute. To investigate incidence, cause, maternal and perinatal outcome. Maternal Data includes incidence, age, parity, gestational age, risk factors, intra-operative events, amount of blood loss. Other causes of APH-Placenta praevia and extra-placental causes are excluded. Neonatal data includes Term/preterm, Birth weight, NICU admission, perinatal morbidity and mortality.

Results: Total number of deliveries from October 2017 to September 2018 were 7010 . Total number of abruptio placenta cases were 55. This study shows increased incidence of severe preeclampsia with abruption. Increasing age as predisposing factor. Mean age of abruption was 26-30 years mainly seen in term pregnancy. Mode of delivery varied. Major complication were PPH and shock managed with blood products.

Conclusions: This study reveals increasing age, parity, severe preeclampsia are risk factors. Routine and regular antenatal checkup early detection and correction of Preeclampsia, anemia helps to deduce no of abruption and improving maternal and fetal outcome though maternal morbidity is reduced with modern management of abruption, Timely diagnosis and intervention is necessary. Team efforts by obstetricians, anesthetist and neonatologist is required for better maternal and fetal outcome.

Keywords: Abruption, Severe pre-eclampsia, Shock

\section{INTRODUCTION}

Placental abruption is the most common cause of antepartum haemorrhage. Defined as premature separation of normally implanted placenta before delivery of fetus. It is a serious obstetric condition that increases maternal and neonatal morbidity and mortality. The existing clinical severity rely exclusively on fetal and maternal complications without considering neonatal or preterm delivery related complications. Incidence appears to be increasing probably due to increase in prevalence of risk factors. Incidence around $1 \%{ }^{1,2}$ Primary cause is not known but main precipitating and aggravating factors are age, parity, anaemia, poor nutrition, preeclampsia, PROM, previous history of abruption, previous LSCS/MTP. ${ }^{3-9}$ Hypertensive disorder of pregnancy is associated with $2.5 \%$ to $17.9 \%$ of placental separation. Detached portion of placenta is unable to exchange gases and nutrients when remaining fetoplacental units unable to compensate for this loss of function- fetal compromise abruption due to rupture of uterine spiral artery. ${ }^{10}$ Bleeding into decidua leads to separation of placenta. Haematoma formation further separates the placenta from uterine wall causing compromise of blood supply to the 
fetus. ${ }^{11,12}$ Types are I-Revealed blood tracks between the membranes and escapes through vagina and cervix. IIblood collects behind the placenta with no evidence of vaginal bleeding. Abruption may be partial or total. Pain and vaginal bleeding hallmark of abruption. However, two-third of abruption cases are accompanied by fetal or neonatal complications. So clinically classification for abruption should include not only maternal complications but also adverse fetal and neonatal outcomes includes intrauterine growth restriction and preterm delivery. To define severity of abruption should anyone of maternal (disseminated intravascular coagulation, hypovolemic shock, blood transfusion, shock, hysterectomy, renal failure) or fetal (intrauterine death, preterm delivery). There are no laboratory tests or diagnostic procedures to definitively diagnosis placental abruption. Maternal and fetal survival depends on early diagnosis and intervention. However, some studies may be conducted in the effort to eliminate other conditions as well as to provide baseline data. ${ }^{13-15}$

The objective of present study was to determine incidence, cause of abruption, management-mode of delivery, maternal and perinatal outcome of abruptio placenta in Govt Theni medical college in one year.

\section{METHODS}

Retrospective observational study carried out by analyzing casesheets of documented abruption placenta during period of October 2017 to October 2018 (7010 patients) at Govt Theni medical college-tertiary care institute. To investigate incidence, cause, maternal and perinatal outcome.

All study patients underwent complete obstetric examination and clinical workup done. Fetal wellbeing assessed by cadiotocography and ultrasonogram. Maternal Data includes incidence, age, parity, gestational age, risk factors (PIH, GDM, Polyhydraminos, Twins), Previous history of abruption, PROM, intra-operative events (amount of blood loss including retroplacental clots). Neonatal data includes Term/preterm, Birth weight, NICU admission, perinatal morbidity and mortality. Ultrasonogram helps to confirm retroplacental clots and to assess severity of abruption.

\section{Inclusion criteria}

- Gestational age $>30$ weeks, primi, $2^{\text {nd }}$ gravid, Nonsever preeclampsia, Prev LSCS, Polyhydraminos.

\section{Exclusion criteria}

- High parity index, twins, GDM, known case of medical disorders, obesity, other causes of antepartum haemorrhage-placenta praevia, indeterminate origin

\section{RESULTS}

Total number of deliveries from October 2017 to September 2018 were 7010. Total number of abruptio placenta cases were 55. Increasing age as predisposing factor. Mean age of abruption was 26-30 years, 43.6\%. Least incidence in $<20$ years- $9.07 \%$. This study shows increased incidence of severe preeclampsia with abruption (Table 1).

Table 1: Risk factors.

\begin{tabular}{|l|l|}
\hline Risk factors & Percentage \\
\hline Severe preeclampsia & 52.7 \\
\hline Chronic hypertension & 10.9 \\
\hline Premature rupture of membrane & 3.6 \\
\hline Polyhydraminos & 3.6 \\
\hline Trauma & 1.8 \\
\hline
\end{tabular}

Clinical presentation includes abdominal pain 60\%, excessive show 20\%, decreased perception of fetal movements 205 (Figure 1).

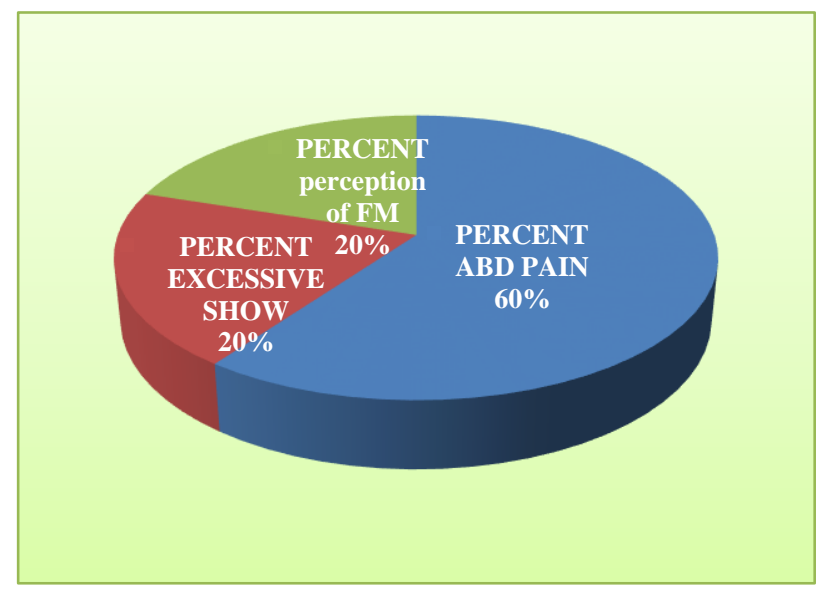

Figure 1: Clinical presentation.

Clinical sign $80 \%$ tense and tender, $20 \%$ Tetanic contractions and $10 \%$ blood stained liquor (Figure 2).

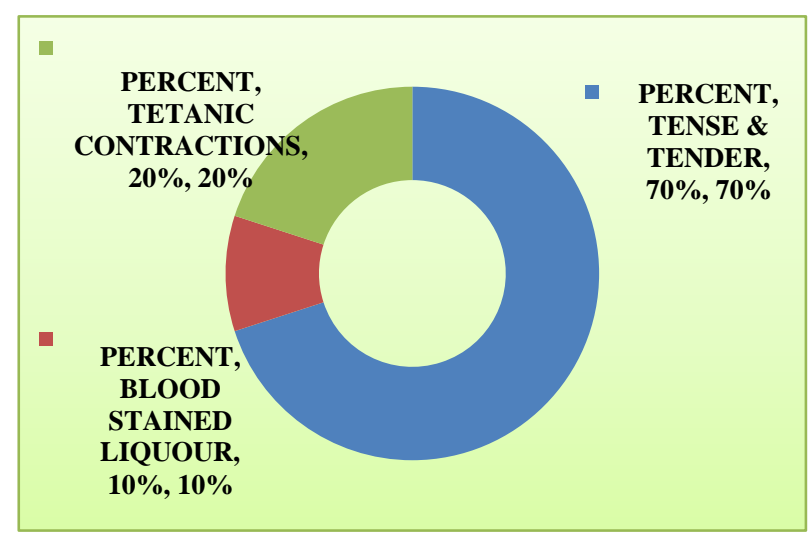

Figure 2: Clinical sign. 
Based on grading of abruption, $56 \%$ of cases Grade II, $30 \%$ Grade III, 16\% Grade I. All 55 cases required blood transfusion $(100 \%)$, of which $21 \%$ of Transfusion were specific to Postpartum Blood loss in addition to Retroplacental blood loss. DIC (3.8\%) cases were reported. Acute renal failure (1 case) required 9 cycles of Haemodialysis. One case of Caesarean Hysterectomy proceeded in view of atonic PPH with failed medical management (Table 2).

\section{Table 2: Complications.}

\begin{tabular}{|l|l|}
\hline Complications & No. of cases \\
\hline Blood loss & $100 \%$ \\
\hline Postpartum haemorrhage & $21 \%$ \\
\hline Disseminated intravascular coagulation & $3.8 \%$ \\
\hline Acute renal failure & $1.8 \%$ \\
\hline Hysterectomy & $1.8 \%$ \\
\hline
\end{tabular}

Regarding fetal outcomes, $72 \%$ had live birth. $28 \%$ fetal compromised as IUD/stillborn. $10 \%$ died in early neonatal period due to prematurity and growth restriction.

\section{DISCUSSION}

Abruption is one of the serious complications of pregnancy, as it leads to both poor maternal and fetal outcome. About 7010 Antenatal patients followed of which 55 patients landed in abruption. Incidence in this study $7.7 \%$ Signs and symptoms of abruption vary depending upon severity of bleeding and degree of separartion of placenta. Abruption can occur at any stage of pregnancy. $36-38 \mathrm{wks}$ more vulnerable period in this study. Authors found $48 \%$ comes under maternal age $<20$ years and age $>35$ years. $^{4-8}$ Risk association $52 \%$ preeclampsia $10 \%$ chronic HTN patient associated with abruption. 2-5 fold increased rise in prev LSCS. ${ }^{4-8}$ Multiparity 2 fold risk. Hypertension and multiple gestation have long been associated with increased risk of placental abruption and authors too found the same. ${ }^{16-18}$ In present analysis around $70 \%$ cases undergone caesarean section in view of unripe cervix and maternal condition. $30 \%$ vaginal delivery. Some women underwent CS even with dead baby in view of deteriating maternal condition. Postpartum haemorrhage most common complication. $100 \%$ compensated with blood products. $2^{\text {nd }}$ most common DIC which is prevented by transfusion of fresh frozen plasma. ARF only one case found in this study. Sher G observed $10-20 \%$ patients with abruption presented with DIC and fetal compromise. ${ }^{19}$ ARF and pulmonary edema most common cause for maternal mortality. Nil in this study. Fetal-28\% fetus compromised with grade 3 abruption (presented as intrauterine death). $72 \%$ livebirth of which $10 \%$ died due to prematurity and growth restriction due to preeclampsia. $40 \%$ babies weight $>3 \mathrm{~kg}, 50 \%>2.5 \mathrm{~kg}$, $10 \%<2.5 \mathrm{~kg}$. Preterm gestation has been reported more often, (even up to $60 \%$, by Rana et al, $40 \%$ by Chang et al and in the present analysis also, it was $37.2 \% .^{20,21}$ Ananth et al, and Pariente et al, report that small gestational age and hypertensive disorders which reflect chronic vascular dysfunction have strong association with placental abruption. ${ }^{3,22}$ In the present study FGR cases were less than overall FGR cases. The sheet anchor of treatment in cases of placental abruption is resuscitation, termination of pregnancy with amniotomy and oxytocics, timely CS depending on maternal and foetal condition, and the same has been done with some increase in maternal survival improved but perinatal deaths have been persisting rather increased. Cases of placental abruption have been increasing, many with no obvious cause though some cases had risk factors like hypertension, multiple pregnancy, perinatal deaths have been more in last decade though maternal deaths could be prevented. Research needs also to continue about causes so that more can be done for prevention. Awareness needs to be amongst these women and health providers for early health seeking, early diagnosis and timely appropriate management. Routine antenatal checkup, correction of anaemia, timely referral, timely caesarean section, liberal blood and blood components transfusion and good neonatal intensive care unit will help for better perinatal and maternal outcome.

\section{Funding: No funding sources Conflict of interest: None declared Ethical approval: Not required}

\section{REFERENCES}

1. Tikkanen M. Placental abruption: epidemiology, risk factors and consequences. Acta Obstet Gynecol Scand. 2011;90:140-9.

2. Oyelese Y, Ananth CV. Placental abruption. Obstet Gynecol. 2006;108:1005-16.

3. Miller C, Grynspan D, Gaudet L, Ferretti E, Lawrence S, Moretti F, et al. Maternal and neonatal characteristics of a Canadian urban cohort receiving treatment for opioid use disorder during pregnancy. J Dev Orig Health Dis. 2018:1-6.

4. Zamani E. Kerman, Iran: School of Medicine, Kerman University of Medical Sciences; 2009. Study of the frequency of obstetrical antepartum hemorrhage and the causes among pregnant patients at tending the center of Afzalipoor Hospital, Kerman. PhD Thesis.

5. Abbasi RM, Rizwan N, Mumtaz F, Farooq S. Maternal outcome among abruption placentae cases at a University Hospital of Sindh. JLUMHS. 2008;7:106-9.

6. Ananth CV, Smulian JC, Demissie K, Vintzileos AM, Knuppel RA. Placental abruption among single to and twin births in the United States: Risk factor profiles. Am J Epidemiol. 2001;153:771-8.

7. McDonald SD, Vermeulen MJ, Ray JG. Risk of fetal death associated with maternal drug dependence and placental abruption: A population-based study. J Obstet Gynaecol Can. 2007;29:556-9.

8. Tikkanen M, Nuutila M, Hiilesmaa V, Paavonen J, Ylikorkala O. Clinical presentation and risk factors 
of placental abruption. Acta Obstet Gynecol Scand. 2006;85:700-5.

9. Matsaseng T, Bagratee JS, Moodley J. Pregnancy outcomes in patients with previous history of abruption placentae. Int $\mathbf{J}$ Gynaecol Obstet. 2006;92:253-4.

10. Workalemahu T, Enquobahrie DA, Gelaye B, Sanchez SE, Garcia PJ, Tekola-Ayele F, et al. Genetic variations and risk of placental abruption: A genome-wide association study and meta-analysis of genome-wide association studies. Placenta. 2018;66:8-16.

11. Plowman RS, Javidan-Nejad C, Raptis CA, Katz DS, Mellnick VM, Bhalla S, et al. Imaging of Pregnancyrelated Vascular Complications. Radiographics. 2017;37(4):1270-89.

12. DeRoo L, Skjærven R, Wilcox A, Klungsøyr K, Wikström AK, Morken NH, et al. Placental abruption and long-term maternal cardiovascular disease mortality: a population-based registry study in Norway and Sweden. Eur $\mathbf{J}$ Epidemiol. 2016;31(5):501-11.

13. Ananth CV, Wapner RJ, Ananth S, D'Alton ME, Vintzileos AM. First-trimester and second-trimester maternal serum biomarkers as predictors of placental abruption. Obstet Gynecol. 2017;129(3):465-72.

14. Arlier S, Adiguzel C, Yilmaz ES, Seyfettinoglu S, Helvacioglu C, Ekin GU, et al. The role of mean platelet volume and platelet distribution width in the prediction of placental abruption. J ObstetGynaecol. 2016;36(7):950-3.

15. Saphier NB, Kopelman TR. Traumatic Abruptio Placenta Scale (TAPS): a proposed grading system of computed tomography evaluation of placental abruption in the trauma patient. Emerg Radiol. 2014;21(1):17-22.
16. Salihu HM, Bekan B, Aliyu MH, Rouse DJ, Kirby RS, Alexander GR. Perinatal mortality associated with abruptio placenta in singletons and multiples. Am J Obstet Gynaecol. 2005;193(1):198-9.

17. Tikkanen M, Nuutila M, Hiilesmaa V, Paavonen J, Ylikorkala O. Prepregnancy risk factors for placental abruption. Acta Obstet Gynaecol Scand. 2006;85(1):40-4.

18. Abu-Heija A, al-Chalabi H, el-Iloubani N. Abruptio placentae: risk factors and perinatal outcome. J Obstet Gynaecol Res. 1998;24(2):141-4.

19. Sher G. Pathogenesis and management of uterine inertia complicating abruptio placentae consumption coagulopathy. Am J Obstet Gynecol. 1977;129:16470.

20. Rana A, Sawhney H, Gopalan S, Panigrahi D, Nijhawan R. Abruptio placentae and chorioamnionitis-microbiological and histologic correlation. Acta Obstet Gynaecol Scand. 1999;78(5):363-6.

21. Chang YL, Chang SD, Cheng PJ. Perinatal outcome in patients with placental abruption with and without antepartum hemorrhage. Int $\mathbf{J}$ Gynaecol Obstet. 2001;75(2):193-4.

22. Ananth CV, Smulian JC, Vintzileos AM. Incidence of placental abruption in relation to cigarette smoking and hypertensive disorders during pregnancy: a meta-analysis of observational studies. Obstet Gynaecol. 1999;93(4):622-8.

Cite this article as: Sambath S, Rukmani VVH, Subalakshmi S. Abruptio placenta retrospective study: maternal and fetal outcome. Int J Reprod Contracept Obstet Gynecol 2019;8:1355-8. 